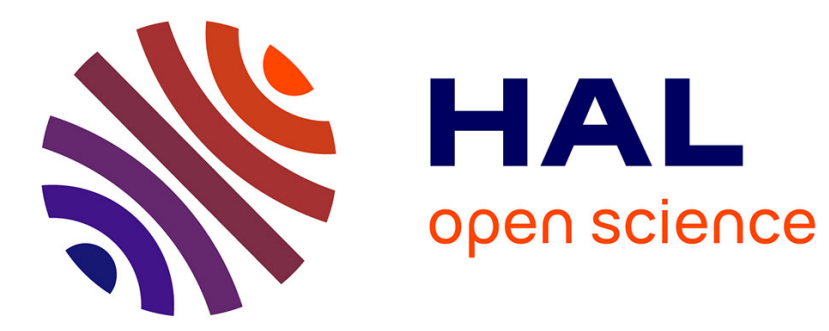

\title{
Facts, Norms and Expected Utility Functions
}

Sophie Jallais, Pierre-Charles Pradier, David Teira

\section{To cite this version:}

Sophie Jallais, Pierre-Charles Pradier, David Teira. Facts, Norms and Expected Utility Functions. History of the Human Sciences, 2008, 21 (2), pp.45-62. 10.1177/0952695108091414 . halshs-00274361

\section{HAL Id: halshs-00274361 https://shs.hal.science/halshs-00274361}

Submitted on 18 Apr 2008

HAL is a multi-disciplinary open access archive for the deposit and dissemination of scientific research documents, whether they are published or not. The documents may come from teaching and research institutions in France or abroad, or from public or private research centers.
L'archive ouverte pluridisciplinaire HAL, est destinée au dépôt et à la diffusion de documents scientifiques de niveau recherche, publiés ou non, émanant des établissements d'enseignement et de recherche français ou étrangers, des laboratoires publics ou privés. 


\section{FACTS, NORMS AND EXPECTED UTILITY FUNCTIONS}

Sophie Jallais, Pierre-Charles Pradier \& David Teira*

\section{ABSTRACT}

In this paper we want to explore an argumentative pattern that provides a normative justification for expected utility functions grounded on empirical evidence, showing how it worked in three different episodes of their development. The argument claims that we should prudentially maximize our expected utility since this is the criterion effectively applied by those who are considered wisest in making risky choices (be it gamblers or businessmen). Yet, to justify the adoption of this rule, it should be proven that this is empirically true: i.e., that a given function allows us to predict the choices of that particular class of agents. We show how expected utility functions were introduced and contested in accordance to this pattern in the $18^{\text {th }}$ century and how it recurred in the 1950 s when M. Allais made his case against the neobernoullians.

\section{CORRESPONDING AUTHOR:}

David Teira

Dpto. de Lógica, Historia y Filosofía de la ciencia. UNED

Paseo de Senda del rey 7 | 28040 Madrid (Spain)

dteira@fsof.uned.es

\section{ACKNOWLEDGMENTS:}

Comments from various audiences are gratefully acknowledged, especially those of the Logos Colloquium (Barcelona, June 2005), the $7^{\text {èmes }}$ Journées d'Economie Expérimentale (Rennes, June 2005) and the History of Economics Society Conference (Grinnell, June 2006). Floris Heukelom and two anonymous referees provided useful suggestions. Teira's contribution has been supported by the grants BF2003-04372 and AECI 2004 18/03/P

\footnotetext{
* Respectively, EconomiX, Université Paris-I Panthéon Sorbonne; Samos-Matisse, Université Paris-I Panthéon Sorbonne, and Dpt. of Logic, History and Philosophy of Science (UNED).
} 


\section{FACTS, NORMS AND EXPECTED UTILITY FUNCTIONS}

Expected utility functions (EUF) are considered the «industry standard» to model decisionmaking processes, especially in economic theory: the hypothesis states that among an array of uncertain outcomes, an agent will choose the sequence of events which maximizes the addition of the utility of each one of them weighed by its probability. However, the number of empirical deviations documented by psychologists and experimental economists suggest that their positive basis are not as solid as it was originally expected in the early $1950 \mathrm{~s}$. At that point, there were many who argued, after Milton Friedman (1953: 21), that there was evidence enough to grant a positive status to EUF-grounded models on the basis of their predictive success alone. However, there were already empirical failures, such as Allais paradox, that prompted a different response: Leonard Savage (1972: 67) argued that EUF should be incorporated into a normative theory of decision-making, so that the rationality of a choice be judged according to the mathematical axioms defining EUF. Any deviation would constitute a transgression of a decision rule, rather than a simple exception to a model.

Both approaches assumed a dichotomy between facts and values (or positive and normative economics or decision theory). Yet it seems as if this gap had often been bridged in both directions. The normative appeal of the principles defining EUF may provide indirect evidence of their empirical plausibility, in spite of contrary evidence (Starmer 2005: 278). In this paper, we will focus on an alternative direction of fit: how the empirical content captured by EUF contributes to their normative standing.

The normativity of expected utility theory (EUT) is very often conceived on a priori grounds without empirical counterparts: we would be compelled to act in accordance to its postulates by virtue of intuition alone. E.g., EUT assumes, as every utilitarian theory, that we want the most to achieve our goals; by a purely conceptual examination of its axioms, it can be shown that EUT secures the coherence in our decisions that is necessary (though not sufficient) to rationally attain that goal (e.g. Savage 1972: 102). This justification of EUT as a prescriptive rule is thus similar to many other moral arguments in the analytic tradition. EUT would transform our intuitions about rational decision-making into normative statements of general scope. Testing them through series of examples and counterexamples (e.g., the Allais paradox) would lead us either to more refined versions of the theory or to an alternative one that is judged more concordant with our intuitions.

However, just as empirical EUT receives some support from normative considerations, its normative cogency also benefits from empirical evidence in a way that, in our opinion, cannot be captured by this aprioristic argumentative strategy. It has often been signalled that rationality in economics is used like a thick term in which the normative and positive dimensions usually cannot be factored out (e.g., Mongin 2006). We want to show in this paper how they both interrelate in the prescriptive justification of EUF, according to a different argumentative pattern that recurs throughout two centuries. The use of EUF would be here justified as long as they captured the decision rule actually applied by those considered wisest in making uncertain choices (businessmen, gamblers, insurers, etc.). The underlying consequentialist principle is that imitating them is the best approach to achieve 
our goals, since their practical success provides compelling evidence of the virtues of their decision rules -independently of whether we can explain it in a priori analytical terms. We would be thus justified in adopting EUF as one of such rules if it can be empirically shown that they effectively predict the choices of these experts.

This approach to normativity stems from the Aristotelian tradition, in which the opinion of the wisest (ta endoxa) is often considered the best possible premise for practical reasoning and should be adopted as such in our moral deliberations (Vega 1998). Kant excluded these sort of prudential concerns from the realm of ethics in favour of more general, inconditional, imperatives. Yet, the justification of EUF as prescriptive rules has drawn on this Aristotelian strategy since their very inception until our days. The purpose of this paper is to show how this argumentative pattern works in three different cases, to illustrate its cogency and scope. In $\S 1$, we will briefly discuss how EUF were originally conceived as a wise decision rule that solved the normative dilemma posed by the St. Petersburg paradox. In $\S 2$, we will analyze how Condorcet contested this solution since it failed to capture the criterion actually applied by the most expert decision-makers. In $\S 3$, we will see that precisely this objection recurred when Allais developed his paradox against the American School and how he defended his own theory as a better approximation to the expert's criterion. In view of all this, we will briefly discuss by way of conclusion to what extent this strategy is still defensible to ground any prescriptive rule.

\section{1730: EUF APPEAR}

Our first thesis is that EUF originally appeared embedded in a normative rule that allowed for the calculation of the just price of a gamble. Though Bernoulli's invention is often presented as the first positive model of uncertain decision-making, we should pay more attention to the arguments that justified their introduction to appreciate its normative character $^{1}$. EUF came indeed to provide a general solution to a normative dilemma, known by early probability theorists as the Problem of Points (Franklin 2001: 258-320): how to distribute the stake among the gamblers when their game had been interrupted an one of them had a certain advantage that, intuitively, gave him the right to expect a bigger share.

Let us briefly remind these antecedents. Pascal and Huygens introduced the concept of mathematical expectation to calculate such distribution on the basis of a legal analogy that any gambler could consider fair. According to a legal tradition that they probably received from the Schoolmen (Coumet 1972), a gamble could be compared to a mercantile insurance contract, in which both the insurer and the merchant assumed a risk in common expecting a certain payoff. On that principle, they should agree on a just price for the insurance balancing uncertainty and gain. Drawing on this comparison, Huygens solved the Problem of Points with the statement of a precise proportion between the wager (the price to take part in the game) and the likelihood of obtaining a particular reward. The rule would be stated as follows: a fair game would be that in which you bet what you could mathematically expect to win.

Yet, as a result of the application of this rule to certain gambles, a certain paradox appeared. The jurist Nicolas Bernoulli (1687-1759) discovered in 1713 that there was a game of which the expected gain was apparently infinite ${ }^{2}$. Imagine a coin-toss game, in

\footnotetext{
${ }^{1}$ The historical details supporting the argument of this section are thoroughly discussed in Teira 2006.

${ }^{2}$ N. Bernoulli's texts on the St. Petersburg gamble can be found in J. Bernoulli 1975: 557-67.
} 
which the payoff function is $2^{\text {n-1: }}$ i.e., A pays $B$ a coin if the coin turns up heads the first time $\left(2^{1-1}=2^{0}\right)$, two coins if this result takes place in the second toss $\left(2^{2-1}\right)$, four if it was in the third $\left(2^{3-1}\right)$, and so forth. Considering that the corresponding probability amounts to $1 / 2^{\mathrm{n}}$, the mathematical expectation of the game is given by an infinite geometric series of common ratio 1 , that is, divergent ${ }^{3}$. For more than two centuries, it was simply taken to be infinite (Jorland 1987). In other words, no fair price could be calculated for this game in accordance to the general rule established by Pascal and Huygens. Intuitively, we could not deem a just price (valeur juste) such an infinite mathematical expectation, since it seemed extremely unlikely to obtain it. Therefore, a revision of the ruled was called for to ensure that it could be generally applied (selon la justice) without incurring in paradoxes.

Daniel Bernoulli undertook this task when his cousin Nicolas communicated him the paradox and submitted his results for publication in 1730-31 volume of the Commentarii Academiae Scientiarum Imperialis Petropolitanae — after which the St. Petersburg paradox was named ${ }^{4}$. Being a graduate in philosophy from Basel, Daniel was probably aware of the existence of different sorts of arguments to justify a norm, and this is crucial for a proper assessment of his solution to the paradox. Instead of a general rule to calculate the just price of games, he proposed a deliberative criterion (non judicia, sed consilia) that could be applied discretionally: when choosing between uncertain prospects, try to maximize your expected utility. The mathematical expectation of a gamble could be calculated ignoring the personal circumstances of those who were to take part in the game. It was a rule as impartial in its generality as any judge would wish, and St. Petersburg paradox arised thereof: how could there be an exception? In the Bernoullian approach, it ceased to be so, since the utility that each particular gambler could derive from the expected gain (emolumentum lucri) was key to calculate the convenience of betting.

Moreover, Bernoulli argued that this utility displayed a concave shape ("any amount of money is necessarily worth more to a less wealthy man") which bounded the increase of the payoff function, solving the mathematical side of the paradox. To account for this particular shape, and justify his decision rule, Bernoulli argued that his functions captured and generalized the criteria implicitly applied by the most experienced decision makers, those who are of «fairly judicious» (quivis cordatus) -namely merchants and insurers.

[T] hough a person who is fairly judicious by natural instinct might have realized and spontaneously applied much of what I have here explained, hardly anyone believed it possible to define these problems with the precision we have employed in our examples. Since all our propositions harmonize perfectly with experience, it would be wrong to neglect them as abstractions resting upon precarious hypotheses. (Bernoulli [1738] 1954: 31)

In other words, Daniel's rule made explicit the rule spontaneously applied by the wisest decision-makers ("the procedure customarily employed by merchants in the insurance of commodities transported by sea" (Bernoulli [1738] 1954: 29), so that we would be "well advised" (p. 30) if we adopt it for our own benefit when we face uncertain choices. In 1731, Daniel wrote to Nicolas: "If only the Bernoullis, who lost so much when the Müllers got

\footnotetext{
${ }^{3}$ I.e., $\sum_{1}^{\infty} \frac{2^{n-1}}{2^{n}}$

${ }^{4}$ The latin text can be found in D. Bernoulli 1982. Its standard English translation is Bernoulli [1738] 1954.
} 
bankrupt, paid attention to the very principles that I establish actually, they would probably not have lost as much» (Daniel to Nicolas Bernoulli, 4/7/1731, apud J. Bernoulli 1975: 565-66). Nicolas bitterly answered the following year: «Man muß nicht zu viel Eyer in ein Korb legen, say our fellows from Basel. But what would you do if you needed to make the most of your money by crediting it to merchants, without being allowed to divide it up?» (ibid.)

Bernoullian EUF ground thus a prescriptive rule for decision-making, whose normative force stems from its concordance with the actual practice of those socially acknowledged as best experts in dealing with risky prospects. Their practical success weights more than any a priori rationale in terms of the mathematical properties of these functions (e.g., long run considerations such as those examined by Daniel's uncle, Jacob, in the fourth part of his Ars Conjectandi). Therefore, we may expect that the empirical accuracy of EUF to capture wise decision rules will be a crucial part of their normative justification. We may see to what extent this is so examining a not very well-known response that the Bernoulli functions received from the Marquis de Condorcet.

\section{1780: THE DEBATE ABOUT EUF}

The fact that Condorcet was the favourite disciple of D'Alembert, who had been in turn the intellectual arch-enemy of Daniel Bernoulli, could perhaps account for the underlying motivation of his discrepancy with the latter's rule. Provided that decisions between uncertain alternatives were made weighting the utility of the expected gains with their respective probabilities, Condorcet found much more objectable to claim it existed a continuous series of values derived from a concave utility function that could account for every possible decision a rational agent could made. In other words, he did not dispute the normative status of Bernoulli's rule, but rather its empirical specification.

Condorcet swam against the tide. Any XVIII ${ }^{\text {th }}$ century European could have quoted the socalled widow offering parabola (Mark 12, 41-44), which exemplified the concavity of the utility function: any amount of money is necessarily worth more to a less wealthy man. A short time after the publication of the Bernoulli paper, the distinction between necessaries and superfluities was to become the matter of the controversy about luxury. Whatever opinion one may have had on this issue, the idea that marginal utility of wealth decreased (i. e. concavity of utility) was universal among thinkers interested in social matters (see e. g. Pradier 1996). Except for Condorcet:

[B]ecause this principle is itself hypothetical, any amount of money is necessarily worth more to a less wealthy man; but it seems to us arbitrary to choose either Daniel Bernoulli's law or any other one which could fulfil the same conditions. (Condorcet 1994: 584)

Bernoulli had written ([1738] 1954: 25): «any increase in wealth, now matter how insignificant, will always result in an increase in utility which is inversely proportionate to the quantity of goods already possessed»; this led through integration to a logarithmic utility function. Yet, Condorcet disliked this kind of both too simple and too precise hypothesis - he had already criticized Verri's law of demand which was formulated in the 
same way ${ }^{5}$. Though other hypotheses had been proposed as to the shape of the function such as Cramer's or Buffon's 6 , no one had taken issue with Bernoulli's as straightforwardly as Condorcet $\mathrm{did}^{7}$.

The example chosen by Condorcet in the 1784 reveals the target of his objection: the accuracy of the model describing the merchant's propensity to buy insurance contracts Against Bernoulli, it is contended that rationality does not always lead to computing a certainty equivalent of random prospects. Merchants are only supposed to decide whether they will accept or deny an offer, or which random prospect they will choose among a given set.

A reasonable man should enter into business only if he finds a fairly high probability to get his investment back, with common interest and the price of his labour.

Such man will doubtless require the probability not to lose his funds wholly (saving at least what is needed for the subsistence of his family) to be close to certainty; as well as the probability not to diminish his funds by more than a given amount to be very large too. (Condorcet [1784] 1994: 86)

Condorcet then argues that both a fairly high probability to earn one's life together with a very small probability not to lose the necessary funds for subsistence are required in order to undertake any investment. In other words, if the justification of Bernoullian EUF depended on how they captured and generalised our intuitions about how the wise entrepreneurs decide, Condorcet replies that they fail to do so. They are misspecified in two ways, for attention should be paid to probability, and not only to the utility of gains. Once defined, the model will not give us a continuous series of expected gains but limit-values on which decisions should be made (minimal anticipated profit in order to undertake, minimum selling price given the insurance rate, etc.).

However, Condorcet could only draft an alternative rule. Unlike Bernoulli, he did not plan to account for prices of aleatory contracts, but wanted instead to set rational boundaries in the negotiation between two parties $^{8}$ _ perhaps a reminiscence of Turgot (Hervier 1997:

\footnotetext{
${ }^{5}$ Condorcet wrote in 1771 to Pietro Verri: «You say that the price is inversely proportional to the number of sellers, and proportional to the number of buyers. I know very well that the price rises when the number of buyers do, so does it declines when the number of sellers rises; but shall we say that the variations are proportional? Thus, the mathematical language, in this case, as well as in any other of this kind [emphasis added], far from leading to more precise ideas, seems to me misleading; I think the author should have preferred ordinary language if only he did not want to make a rigorously exact statement [e. a.]» (Condorcet [*], 1994, pp. 70-71).

${ }^{6}$ Cramer proposed two utility function: one is the square root of wealth, the other has an upper limit. See Cramer [1728] 1975: 561. Buffon, after a trip to Geneva where Cramer lived agrees on both the upper limit of utility and the decreasing marginal utility of wealth (see Buffon [1777] 1977): «[One] would not be, for instance, happier with a thousand of million than with a hundred...» (apud Weill 1961: 117).

${ }^{7}$ D'Alembert (1768 [*]: 77) wrote about the other theories that they «all rest on arguments that do not belong to the question, such as the condition $\&$ fortune of the players. Therefore these solutions contradict one another, and annihilate themselves». This reminds us of Condorcet's argument : one can not choose between arbitrary hypothesis.

${ }^{8}$ «The insurance rate results from competition, it is for every kind of risk determined by some mean between that part of profit the merchant can give away, and that is necessary for the insurer to have a very high probability no to lose. The more competition there will be between merchants and insurers, the closer the
} 
87-ff), who had been his political mentor. Yet, the justification for any rule he could have proposed was found again in the example of those who successfully deal with risky choices:

[We need to] learn how men, who are known to be wise and whose projects succeeded, practically solved the same problem. For instance, what has been the probability not to lose that insurers obtained from various insurance bureaus who carried on their business profitably. (Condorcet [1784] 1994: 492)

After his 1784 piece, Condorcet returned twice to this topic but did not achieved a complete specification of the rule. His main concern was to settle a probability threshold for decision making by empirical means. In 1785, the problem seems to be there were too many relevant thresholds (and therefore, no definite decision rule):

The limit of probability, the value beyond which we shall not fall, can not be given a fixed value. It can and must fluctuate according to the disadvantages that result from error or from lack of decision that impairs action. It must depends above all on the subject at hand. (Condorcet [1785] 1986: 73)

Later, Condorcet offered an indirect evaluation of the thresholds. Rather than looking for every one of the aforementioned thresholds («lose his funds wholly», "saving at least what is needed for the subsistence of his family», «not to diminish his funds by more than a given amount», «get his investment back», "with common interest and the price of his labour»), Condorcet focuses on the concept of moral certainty, i. e. a probability so low that one could rationally neglect the risk associated. Thus, Condorcet argues that only «very light risks to which we expose ourselves willingly» should be considered, such as the risk

$[\mathrm{T}] \mathrm{o}$ die with the ferry during a journey from Calais to Dover. Unfortunately, we do not have any such data; but we can replace them with combinations of elements form the mortality tables.(Condorcet [1787] [*]: $583)^{9}$

Unfortunately, this suggestion did not yield a precise mathematical formula either. However even if Condorcet did not achieved a well rounded decision rule, it is still worth considering the argumentative pattern of both his objections and proposal. He questioned the presumed generality of Bernoulli's decision rule on the basis of the same empirical evidence that was said to support it, i.e., our intuitions about what constituted a wise decision under risk. He tried to state a different rule in which the specification of the probability and the utility functions were specified in accordance with the practice of «men, who are known to be wise» and «whose projects succeeded». I.e, the adoption of the model as a decision rule depends on the acknowledgment of the consequential force of these

mean price will be from the latter, the more the price of goods [sold by merchant] will fall for final consumers.» (Condorcet [1784] 1994: 488)

${ }^{9}$ Condorcet does not say much here, probably because the reference to mortality tables is the beginning of a ramble across the garden of Buffon: the master of Montbard had already set the threshold for moral certainty as the risk for a 56 year old man to die in the present day (Buffon [1777] 1977: 38). Given the aforementioned rivalry between Buffon and D'Alembert, it seems easy to understand why Condorcet does not go into the details. 
cases: it described only the behaviour of a particular group of capable agents, but for the rest of us the wise decision would be to imitate their behaviour by applying the model as a rule to our own particular choices.

\section{1950: EUF REAPPEAR}

After an apparent eclipse of about 150 years (Schlee 1992), EUFs came again to the fore when von Neumann and Morgenstern chose them to append a decision model to their theory of games ${ }^{10}$. Expected utility theory (EUT) was now explicitly presented as a positive technique for the descriptive analysis of economic decisions, free from any normative implications. Yet, in this section we will examine how the argumentative pattern already applied by Bernoulli and Condorcet to justify the prescriptive use of EUF recurs once more.

Within the French community of mathematical economists there were many who doubted the proclaimed scientific success of EUT and a conference was organized in 1952 in Paris to debate it. Maurice Allais, as most French participants, objected to its descriptive relevance through counterexamples, pairs of choices that were supposed to induce violations of EUT. The most famous came to be the Allais Paradox. The decision-maker was sequentially exposed to a couple of equivalent choices: in virtue of the independence axiom, the expected utility of the first pair of alternatives was exactly the same as that of the second pair, so that his election among the first couple should allow us to predict his decision as to the second. Leonard Jimmie Savage treated them as if they were not equivalent during a private lunch with Allais, who tried to get some more responses during the conference ${ }^{11}$ and conducted by mail a survey to the same effect soon afterwards - its results only went to print thirty years later (Allais 1979). By the end of the 1950s the paradox was widely considered an anecdote, even if it may now be read as an anticipation of the experimental results against EUT that were delivered a decade afterwards. Perhaps it seemed somehow acceptable to dismiss those observed deviations from EUT that appeared to be normatively indefensible. Mistakes would not count as refutations (Starmer 2005) ${ }^{12}$.

But we should note here that Allais was contesting EUT simultaneously at both levels: it failed to positively predict the result of certain kind of choices and these cannot be dismissed as normatively irrational. This second argument is of interest here since it will show us how empirical considerations had again a normative impact, both to contest someone else's theory and to justify one's own.

First of all, according to Allais, rationality turns out to be too general a category if we simply define it as obedience to the axioms of EUT: even if we have an ordered set of choices, compliance to the axiom of absolute preference and a suitable probability

\footnotetext{
${ }^{10}$ For an in-depth historical analysis of the content of this section cf. Jallais and Pradier 2005.

${ }^{11}$ In spite of Allais occasional claim that all of them fell into the trap, a careful examination of Allais 1979 shows that only Shackle (who firmly stands against EUF from 1949 on), de Finetti et Malinvaud were caught.

${ }^{12}$ Yet, a methodological justification of such dimissal is quite difficult to build up. Francesco Guala (2000) has tried to rationalize as a Lakatosian monster-barring strategy. Counterexamples against a theory of decision-making can only be considered so when we can capture the exception they represent in terms of another theory, conveying a different idea of rationality. According to Guala, our normative views about rationality would provide some sort of positive heuristics for research, by way of non-refutable hardcore. This strategy, we should add, does only make sense if we accept to treat rationality as a thick term and accept that theoreticians move at will between its normative and positive part. So that if a falsifier for the latter appears, it can only be declared nonsensical on the basis of the former.
} 
distribution, there are in fact many different decision functions, linear in probability, where these three constraints do not bear any analytically tractable functional form (Allais [1952] 1979: 34-41). Why should we choose the particular specification defended by the American School? In other words, which normative intuition about rationality does it capture that makes it so compelling (as to discard other alternatives)? Here is where the argumentative pattern we already observed in Bernoulli and Condorcet recurs. Allais advocates an experimental definition of rationality to test whether the normative intuition captured by EUT is as convincing as it should be:

To observe the behaviour of men whom one has reason in other respects to believe act rationally (Allais [1952] 1979: 79).

"Men whom one has reason in other respects to believe act rationally" are a new instance of the "wise" Condorcetian decision-makers or the "fairly judicious" Bernoullian merchants. But now these experts were identified within a different profession: they were «persons of high scientific achievement, and very well versed in probability theory» (Allas 1979: 466). Here was again the Condorcetian test: if they failed to use a model properly, we should discard the latter as a normative standard rather than blame it on their irrationality. If a talented mathematician such as Savage could not act in accordance with the axioms defining EUT, could someone expect more from an ordinary decision maker? ${ }^{13}$

The burden of proof was thus reversed: EUT supporters must now show that "that persons acting this way are behaving irrationally" (Allais [1952] 1979: 92). The Frenchman boasted: "If somebody does wish to argue the contrary, it would be quite fascinating to hear his grounds!" (Allais [1952] 1979: 92) ${ }^{14}$. Allais' trust in the normative cogency of the practical decisions made by scientists might be rooted in his own education in the Napoleonic École Polytechnique, whose graduates, after a very demanding scientific training, were appointed at the highest positions in the French public industry. Allais was himself a mining engineer, and in such capacity had hold various positions in the French administration from 1937 to 1948. He had cared then about the improvement of the decision rules already applied by his subordinates: in 1949 he had published a study of their efficiency, surveying the statistical data they generated. In 1953 he put to use his ideas on risky decision-making in a report on the convenience of investing in mining explorations in Alger $^{15}$. In other words, Allais was interested in the prescriptive use of decision theory and granted that EUT could play such a role. He only thought it normatively ungrounded.

The «American» supporters of EUT chose not to respond probably not as a result of their simple distaste for normative discussion. As Paul Samuelson put it, «just as you cannot argue about tastes, you cannot, from a purely deductive point of view, argue about axioms»

\footnotetext{
13 «Those surveyed in the context of the 1952 experiment were highly conversant with the theory of probabilities, having generally extensive mathematical knowledge and being persons likely to be commonly considered as "rational" from the standpoint of all the available criteria, apart from any criteria relating to random choice» (Allais 1979: 468). The qualifications of the subjects who later on responded to an additional questionnaire are listed in Allais 1979: 613-614.

${ }^{14}$ His words were echoed years later by other experimental analysts of the violations of EUT: e.g, "Are they foolish ? [...] it seems out of the question summarily to judge their behaviour as irrational: I am included among them" (Ellsberg 1961: 669; emphasis added).

15 «During the years 1953-1954, I undertook concrete application of the theses I had propounded at the 1952 meeting. The opportunity arose in connection with an operational research project for the Bureau de Recherches Minières de l'Algérie.» (Allais 1979: 450)
} 
(CNRS 1953: 143). They preferred not to treat rationality as a thick predicate and restrained themselves to explore the empirical consequences of the theory, leaving its normative dimensions aside. Yet, it is important to notice that those who acknowledged the thickness of rationality conducted the discussion in the terms that distinguished the argumentative pattern we have been examining. Let us briefly consider the following two responses.

After being exposed to the Allaisian test, Savage moved from a positive to a normative understanding of EUT. He granted, like Allais, that its cogency as a rule for wise decisionmaking depended mostly on the judgment of experts ${ }^{16}$. The independence axiom incorporated into EUT would indeed capture a «universally known and recognized» principle, whose «intuitive appeal» is «unique among maxims for wise action» (Friedman and Savage 1952: 468). Therefore, it is not a principle that one would «deliberately violate». Apparently Paul Samuelson was not very willing to accept it, but Savage convinced him using the Dutch book argument: those who do not comply with the axiom expose themselves to serious losses ${ }^{17}$. The decision rule is now justifed a priori as a prerequirement for anyone's practical success: it is a recipe against failure and it can be obtained from purely theoretical considerations, without recourse to experience. Yet, it coincides with the best criterion already in use.

An different take along the same lines was proposed by Jacob Marschak in his 1951 essay "Why "should" statisticians and businessmen maximize "moral expectation"?». The normative dimension is acknowledged straightforwardly, but it is now affirmed a priori: norms are now a matter of logic and at no claim is made as to its actual compliance (Marschak 1951: 493, 505). Yet, those who act against them do not behave reasonably for the usual consequentialist consideration (now a positive one): «in the long run, it pays to be reasonable» (Marschak 1951: 496). In our terms, acting in accordance with EUT delivers practical success ${ }^{18}$. To prove this, Marschak tries to derive from the rule of maximizing expected utility the satisfaction of «the rule of long run success»: under certain assumptions (admittedly not very plausible), it will be almost certain that a sequence of strategies maximizing expected utility will outperform any other utilitarian decision rule (Marschak 1951: 504-5).

Be it to avoid failure or to achieve success, EUT provided an a priori justified rule that captured our intuitions about how wise decisions are made under uncertainty and was, thus, normatively cogent. And we should note here that Allais contested Savage and Marschak's claims to show that no such rule could be attained on mere considerations of principle. Let us briefly discuss his response to see how empirical considerations again came to support his normative case.

In order not to beg the question, argued Allais, rationality should not be a priori identified with a given set of axioms (Allais [1952] 1979: 77-78). He departed thus from a more

\footnotetext{
16 «Success of the maxim in this domain [statistical theory], as in any other area of decision involving uncertainty, depends, not only on its empirical verification for the economic behavior of men at large, but on its acceptability to individuals who are particularly concerned with such decision, as a rule guiding "wise" behavior in the face of uncertainty» (Friedman and Savage 1952: 463n).

${ }^{17}$ «[A]s Savage pointed out to me in a 1950 letter, duplicating a similar argument that had been made by Frank P. Ramsey prior to 1930, if I behave like an Ysidro, I can, so to speak, make book against myself and end up making —or shall I say losing? — money!» (Samuelson 1965: 124)

${ }^{18}$ And, according to Marschak, people should be taught to use EUT to that effect: CNRS 1953, p. 35.
} 
general stance in which it could be defined on the basis of the consistency of someone's ends, be these what they may, and the use of the appropriate means to achieve them (Allais [1952] 1979: 70). Mathematically, he represented this through a functional of the objective frequency function of the psychological values of the expected gains — satisfying the axiom of absolute EUF would constitute here just a possible specification of such functional. More precisely, one in which the dispersion of psychological values about their mean (the impact of the spread of gains and losses) is not taken into account, which led Allais to conclude:

In point of fact, it would be improper to brand a cautious man irrational because he is willing to accept a lower psycho-mathematical expectation as the price of lower dispersion. Nor can a person who enjoys risk as such be labelled irrational, merely because he accepts a lower psycho-mathematical expectation as the counterpart of the availability of some chance of extremely high psychological gain He may be felt to be imprudent -this as it may be- but it seems impossible to say that he is irrational. (Allais [1952] 1979: 70; cf. 86-95 for a discussion of various examples)

In other words, rationality is now separated from prudence, so that acting in accordance to any theory of uncertain decision-making would convey no particular promise of practical success. Against Savage's Dutch book argument, Allais objects that the expected utility of a gain is not psychologically independent of the gains that may be obtained with more certain or uncertain probability (Allais [1952] 1979: 98-99). The fact that people whose rationality is widely acknowledged violate the independence axiom shows that obeying it in all possible situations may actually be irrational (CNRS 1953: 315). As for Marschak's argument, Allais replies (Allais [1952] 1979: 71-72) that most random decisions relate to isolated events in which long-term considerations are irrelevant. Summing up:

The governing factor here is personal psychology. Some will prefer to rely on mathematical expectation, others will attach greater probability to the form of the distribution. No rule of conduct can be considered as more rational than other. (Allais [1952] 1979: 72)

However, prudence alone retained its normative appeal to justify the application of a given decision model, in accordance to our argumentative pattern: «Observation shows that prudent businessmen act as though they were balancing the probable gain $\mathrm{g}$ against the probability P of a loss exceeding X» (Allais [1952] 1979: 92). Their strategy can be easily captured by his theory and implemented for practical purposes. Which he did in 1953 when his advice was sought on the opportunity of mining explorations in Algeria (Allais 1957):

The guiding principle was to offer the Mining Research Office of Algeria a reasonable compromise beween the mathematical expectation of the gains that might be expected and the probability of ruin. (Allais 1979: 451)

To sum up, in 1952 Allais contested not only the predictive value of EUT, but also its normative cogency according to the same argumentative pattern already applied by Bernoulli and Condorcet. Namely, to test the moral cogency of a choice rule depending on its empirical correspondence to admittedly wise decision-making. His case was probably not much appreciated, but let us just a few words on that by way of conclusion

\section{CONCLUDING REMARKS}


We have examined three different episodes in the development of EUF, in all of which a similar argumentative pattern recurs to provide an empirical justification for EUF-based norms. For those who accept the consequentialist principle that, when facing risky choices, it is better to imitate the decision rule applied by those who are acknowledged as experts, the crucial issue is to identify it empirically. Bernoulli tried to capture it in the choices of merchants and insurers using EUF. Condorcet disputed that these wise decision makers estimated their utility and probability as Bernoulli suggested and argued for an empirical elaboration of an alternative rule, which was left unfinished. Allais appealed again to the impossibility to reconcile EUT with the behavior observed in those agents that are widely considered rational and suggested a more concordant alternative to replace it.

Given now that this sort of argument consistently appeared at two crucial stages in the development of EUF, we may wonder why it has been mostly ignored so far. It can be in part explained by the little appreciation for experiments that economists and philosophers alike showed until very recently. As a matter of fact, on the economist' side, experiments on EUT brought again to the fore its normative dimension [*], though without much debate as to the justification of the prescriptive rules derived therefrom. As for the philosophers, at least in the analytic tradition, experiments are just emerging as a source of relevant evidence to test moral theories [*]. We may expect then that a more naturalist approach to normativity will bring more attention to the arguments presented by our three authors.

Yet, even on this basis, it may be argued that they just constitute a very preliminary attempt at the empirical justification of decision rules. First, because the identification of the population of experts (be it merchants, insurers or statisticians) whose decision criteria should be rendered explicit it is as such problematic. It is a broad social category in which we should draw a sample of exemplary decision-makers. Who do we take as such is in itself a matter of normative controversy, that should be settled before any experiment takes place. In addition, since the normative justification we are looking for is consequential, we need to show that these experts owe their practical success - at least in part - to the systematic application of the decision rules under study, and not just to mere chance. Otherwise, the imitation of the experts would yield no prospect of consequential interest. Still, those who want to explore this experimental approach to normative issues can claim the authority of several founding fathers of decision theory to vindicate their enterprise.

\section{REFERENCES}

Allais, Maurice. [1952] 1979. «The Foundations of a Positive Theory of Choice Involving Risk and a Criticism of the Postulates and Axioms of the American School». In Allais and Hagen 1979: 27-145.

Allais, Maurice. 1957. «Method of Appraising Economic Prospects of Mining Exploration Over Large Territories. Algerian Sahara Case Study», Management Science 4.3: 285-347

Allais, Maurice. 1979. «The So-called Allais Paradox and Rational Decision Under Uncertainty». In Allais and Hagen 1979: 437-681

Allais Maurice, Hagen. Ole. (eds.) 1979 Expected utility hypothesis and the Allais Paradox, Dordrecht: Reidel 
Bernoulli, Jacob. 1975 Die Werke von Jakob Bernoulli, v. 3, Basel: Birkäuser Verlag.

Bernoulli, Daniel. 1982. «Specimen Theoriae Novae de Mensura Sortis». In L. P. Bouckaert \& B. L. van der Waerden (Eds.), Die Werke von Daniel Bernoulli (Vol. 2, pp. 223-235). Basel: Birkhauser. (First published 1738)

Bernoulli, Daniel. [1738] 1954. «Exposition of a New Theory on the Measurement of Risk» (L. Sommer, Trans.). Econometrica, 22, 22-36.

Buffon, Georges Louis Leclerc de. [1777] 1977. Essai d'arithmétique morale, in Idem, Un autre Buffon, Paris: Hermann.

CNRS. 1953. Colloque "Econométrie". Paris 12-17 mai 1952. Paris, CNRS.

Condorcet, Jean Antoine Nicolas Caritat de. [1784] 1994. «Assurances (maritimes)». In Idem, Arithmétique politique - textes rares ou inédits (1767-1789), Paris: INED, pp. 485-494.

Condorcet, Jean Antoine Nicolas Caritat de. 1785 [1986]. «"Discours préliminaire" de l'Essai sur l'application de l'analyse à la probabilité des décisions rendues à la pluralité des voix.» In Sur les élections et autres textes, Paris, Fayard, pp. [*].

Condorcet, Jean Antoine Nicolas Caritat de. 1994. Arithmétique politique - textes rares ou inédits (1767-1789), B. Bru et P. Crépel, éds., Paris, INED, 1994.

Coumet, Emile. 1972. «La théorie du hasard est-elle née par hasard?» Annales: Économies, Sociétés, Civilisations, 25, 574-98.

Cramer, Gabriel. 1728. «Letters to Nicolas Bernoulli.» In J. Bernoulli 1975, [*].

D’Alembert, Jean Le Rond. [1768] [*]. «Sur l'analyse des jeux.» In Opuscules mathématiques, ed. [*] vol. IV, Paris, David, pp. 80-92.

Ellsberg Daniel, 1961. «Risk, Ambiguity, and the Savage Axioms», Quarterly Journal of Economics 75, pp. 643-669.

Franklin James, 2001. The Science of Conjecture. Evidence and Probability before Pascal, Baltimore, The Johns Hopkins University Press.

Friedman, Milton. 1953. «The Methodology of Positive Economics». In Idem, Essays in Positive Economics, Chicago, The University of Chicago Press, pp. 3-43.

Friedman, Milton and Savage, Leonard J. 1952. «The Expected-Utility Hypothesis and the Measurability of Utility», Journal of Political Economy 60.6, pp. 463-474.

Guala, Francesco, 2000, «The Logic of Normative Falsification: Rationality and Exeriments in Decision Theory», Journal of Economic Methodology 7.1, pp. 59-93.

Hervier André. 1997. «Juste prix et valeur chez Turgot», Economie et Sociétés, série P. E., $\mathrm{n}^{\circ} 25,1 / 1997$, pp. 71-108.

Jallais, Sophie and Pradier, Pierre-Charles. 2005. «The Allais paradox and its immediate consequences for expected utility theory». In The Experiment in the History of Economics, edited by P. Fontaine and R. Leonard, R, London: Routledge, pp. 25-49. 
Jorland, Gérard. 1987. The Saint Petersburg Paradox 1713-1937. In The Probabilistic Revolution, vol.1, edited by L.Krüger et al., 157-90. Cambridge (Mass.): The MIT Press.

Marschak, J. 1951. "Why "Should" Statisticians and Businessmen Maximize Moral Expectation?», Proceedings of the Second Berkeley Symposium on Mathematical Statistics and Probability, Berkeley, University of California Press, pp. 493-506.

Mongin, Philippe. 2006. "Value Judgments and Value Neutrality in Economics», Economica, 73, pp. 257-286.

Pradier, Pierre-Charles. 1996. [*]

Samuelson, Paul Anthony. 1965. «1965 postscript». I Joseph Stiglitz (ed.). 1966. The collected scientific papers of P. A. Samuelson, Cambridge (Mass.), MIT Press, pp. 124-126.

Savage, Leonard Jimmy. 1972. The Foundations of Statistics. $2^{\text {nd }}$ ed. N.York: Dover Publications.

Schlee, E. 1992. «Marshall, Jevons, and the Development of the Expected Utility Hypothesis», History of Political Economy 24.3, pp. 729-44.

Starmer, Chris. 2005. «Normative Notions in Descriptive Dialogues». Journal of Economic Methodology 12.2, pp. 277-289.

Teira, David. 2006. «On the Normative Dimension of the St. Petersburg Paradox». Studies in History and Philosophy of Science 37 (2006), pp. 210-223

Vega, Luis. 1998. «Aristotle's Endoxa and Plausible Argumentation». Argumentation 12, pp. 95-113.

Weill, François. 1961. «La correspondence Buffon-Cramer», Revue d'historie des sciences 14.2, pp. 97-136. 